\title{
ANTROPOLOGIA URBANA: INTERDISCIPLINARIDADE E FRONTEIRAS DO CONHECIMENTO
}

Gilberto Velho

Nesta etapa avançada de minha carreira, por várias ocasiões, ora prestando depoimentos, dando entrevistas, ora em conferências e aulas, tenho tido oportunidade de fazer comentários e apresentar reflexões em torno do que entendo sobre o trabalho antropológico classificado como Antropologia urbana. É preciso deixar claro que não tenho a intenção de definir, de modo acabado ou restritivo, essa temática que se caracteriza por sua amplitude e heterogeneidade. Assim, certamente, ao apresentar a minha versão, ligada a circunstâncias de minha vida e carreira que, embora não sejam totalmente originais, pois faço parte de um campo de trabalho e conhecimento, não possa deixar de sublinhar uma singularidade inseparável de aspectos pessoais. ${ }^{1}$

O primeiro curso de Antropologia Urbana dado no Museu Nacional foi no primeiro semestre de 1969, sob a responsabilidade do professor Anthony Leeds, então do Departamento de Antropologia da Universidade do Texas, em Austin.Veio dar aula no PPGAS através do convênio vigente na época com a Fundação Ford. Tony Leeds tinha um perfil bastante original e um modo muito próprio de ser antropólogo, com opiniões fortes, às vezes agressivas. Fora aluno da Universidade de Columbia e pesquisara plantation no sul da Bahia antes de mergulhar no mundo das favelas do Rio de Janeiro e outras cidades. Sempre é difícil, e geralmente não é muito saudável, colocar rótulos em autores, assim como nas pessoas em geral. Certamente, nesse caso, pode-se dizer que Leeds não era um herdeiro da Escola de Chicago, em relação à qual tinha diferenças, e era bastante representativo de um liberalismo norte-americano mais à esquerda. Era leitor de Marx e Engels, assim como fortemente interessado na ecologia, sobretudo nas suas implicações associadas a um evolucionismo materialista. Na realidade, o seu perfil teórico não era nada simples, mas o que lhe dava, sobretudo, destaque era sua grande liderança e competência na abertura de frentes de trabalho de campo. Embora tivesse ficado principalmente conhecido por suas pesquisas em favelas, tinha interesse mais geral sobre a questão urbana em várias de suas dimensões. 
Não fez pesquisa só no Brasil, mas foi aqui que passou grande parte de sua carreira de pesquisador, procurando compreender a vida nas favelas como expressão de um sistema de relações sociais e não de modo isolado ou compartimentado. Estava interessado sempre nas formas de relacionamento dentro e entre distintas categorias sociais (ver Leeds, A. \& Leeds, E. 1978). É indiscutível que a questão da habitação exercia particular fascínio sobre ele, e foi justamente através disto que pudemos nos aproximar mais. No curso que deu no nascente PPGAS, abriu a possibilidade para que os alunos desenvolvessem trabalhos sobre diferentes tipos e modos de habitar. Ora, eu estava tendo uma oportunidade única que iria marcar toda a minha carreira. Já desde o curso de graduação, e como pesquisador no antigo Instituto de Ciências Sociais da UFRJ, interessava-me pelo estudo de camadas médias. Ao me casar, ainda estudante na faculdade, fui morar com a então minha mulher, Yvonne, num apartamento dado por meus pais num prédio de conjugados de Copacabana, cujas unidades tinham área de $39 \mathrm{~m}^{2}$.

Não vou aqui me deter nos detalhes e no desenvolvimento do trabalho que realizei na época. Mas é importante assinalar que foi meu ponto de partida para o tipo de Antropologia urbana que vim a desenvolver. Afinal de contas, eu e minha mulher éramos moradores, mesmo que tivesse sido apenas por um ano e meio, do prédio de conjugados. Éramos copacabanenses vivendo num tipo de habitação predominantemente ocupado por pessoas de pequena classe média, alguns estudantes e também certos tipos sociais que viriam a ser importantes na minha carreira, caracterizados na literatura como desviantes. Havia, como já discuti em outros contextos, situações de acusação de prostituição, homossexualismo e uso de drogas. Além disso, vivendo em pleno regime militar, em meio a uma repressão muitas vezes violenta, também existia o permanente risco de denúncia e acusação de subversão (Velho 1977). Enquanto moramos no prédio, em pelo menos duas ocasiões, houve operações de órgãos de repressão, inclusive com mortes.

Acabamos nos retirando, mudando de prédio e de bairro, mas creio que, literalmente, comecei a fazer uma "Anthropology at home", antecipando algumas discussões e desenvolvimentos que foram se dando nos anos que se seguiram (Peirano 2008). No meu caso, era "home" mesmo, pois tinha como foco de minhas pesquisas o prédio em que morava. Embora tivesse feito incursões a outros edifícios de conjugados e, com a ajuda de alunos, buscasse contato com uma população mais diversificada de Copacabana, é inegável que, favorecido por circunstâncias, exercitei o meu papel de antropólogo no lugar onde morava, prédio, vizinhança, bairro e cidade, ou seja, antropólogos ou não, éramos, como os outros, moradores do prédio. 
O apartamento que pertencia a meus pais era habitualmente alugado como fonte de renda, mas minha avó paterna, quando enviuvou, morou alguns meses ali também. Quando me casei, não foi muito fácil a saída dos inquilinos que, na ocasião, ocupavam o apartamento onde viríamos a morar. Era um casal de idosos, entre os 60 e 70 anos. Foi necessária uma negociação com advogados e uma ajuda financeira para que deixassem o imóvel. Sem dúvida, o ambiente era muito diferente do prédio em que eu morara antes com a minha família. Nele, os apartamentos eram bem maiores e os seus moradores eram quase todos proprietários. Predominavam as famílias de militares, geralmente oficiais de major para cima, em termos de Exército, além do pessoal da Marinha, de capitão-de-corveta para cima. Com o passar do tempo, alguns tornaram-se oficiais generais e, praticamente todos, oficiais superiores. Certamente o ethos predominante contrastava com a heterogeneidade aparentemente tumultuada do Edifício Estrela, nome com o qual o batizei na minha dissertação.

O ponto que quero sublinhar é que, partindo do tema da habitação, tão caro a Leeds, desloquei o foco do meu trabalho antropológico para um universo social de que, de alguma forma, eu participava diretamente. Mesmo que soubesse que a permanência no prédio de conjugados era temporária, isso não nos distinguiria de modo tão nítido de outros moradores. É inegável que a nossa origem social nos ligava às camadas médias superiores. O nosso apartamento era decorado de um modo condizente com esses padrões, assim como o nosso estilo de vida em geral. Mas vivíamos ali, convivendo com pessoas não só de origem mais modesta, mas de estilos de vida muito diferenciados. Os desviantes tornaram-se outro objeto privilegiado de pesquisa. De certa forma, representavam um tipo de outro que contrastaria com a normalidade convencional de uma moralidade de classe média. Assim, os acusados de prostituição, homossexualismo e uso de drogas tornaram-se uma possibilidade de pesquisa e reflexão, em busca das diferenças internas a uma sociedade. A grande cidade, produto e produtora de heterogeneidade, era campo propício para essa tarefa, particularmente Copacabana.

Aos poucos, fui descobrindo a literatura interacionista ligada à Escola de Chicago. Ainda no Brasil, li alguns textos de Goffman e, quando fui para os Estados Unidos, em 1971, tive a grande oportunidade de ampliar o meu conhecimento sobre essa corrente de pensamento. Assim, não só Erving Goffman, mas Howard S. Becker, Everett Hughes, Herbert Blumer, Anselm Strauss, W. F. White, Louis Wirth, Georg H. Mead, Robert Park e Willian Thomas tornaram-se referências importantes para o meu trabalho. Já conhecera textos isolados de Park e Wirth, mas agora alargava os horizontes. Um movimento intelectual crucial foi identificar e refletir, de modo 
mais sistemático, sobre as relações entre estes autores e a obra do pensador alemão Georg Simmel, tarefa que até hoje me interessa. A cidade era, simultaneamente, foco e pretexto para o desenvolvimento dessa perspectiva tão fértil e estimulante.

Defendi a minha tese de doutorado em 1975 na USP, sob a orientação de Ruth Cardoso, já numa fase em que estabelecia pontes entre o marxismo, que foi importante nas primeiras fases de minha formação, com o interacionismo e autores cuja classificação não é nada óbvia, por exemplo, Karl Mannheim, Walter Benjamin, Pierre Bourdieu, Lionel Triling e C. Wright Mills. Tanto Simmel como Max Weber (ver bibliografia) já eram referências centrais. As pesquisas que fiz ou supervisionei foram feitas predominantemente em grandes cidades, principalmente no Rio de Janeiro, mas certamente lidavam com questões e temas que se aproximavam do que estava sendo conhecido como Antropologia das sociedades complexas. Esta classificação sempre foi muito problemática, pois fazia parte do ideário antropológico da época reagir contra o evolucionismo tradicional, salientando que nenhuma sociedade poderia ser considerada simples, mas procurou-se entender que a ideia de complexidade remetia a uma combinação de dimensão, presença do Estado, heterogeneidade sociocultural e diferenciação social marcante.

Assim, claramente, o Império Romano era uma sociedade complexa. O mesmo poder-se-ia dizer de diversas outras, como a chinesa, a indiana, a Europa medieval, as civilizações pré-colombianas etc. Fixava-me mais no estudo da sociedade moderno-contemporânea, podendo estendê-la desde o final da Idade Média e Renascimento até o tempo presente. O Brasil, portanto, fazia parte do conjunto de sociedades complexas moderno-contemporâneas, apresentando as características da presença do Estado, de território vasto ocupado por populações e grupos social e culturalmente diferenciados. Sem dúvida, a leitura de autores como Gilberto Freyre, Sérgio Buarque de Holanda, Caio Prado Jr., Celso Furtado, Florestan Fernandes e Raymundo Faoro ajudou-me a pensar o Brasil como uma totalidade. Essas interpretações mais gerais sempre estiveram presentes, de modo implícito e às vezes explícito, no desenvolvimento de meus trabalhos. Como boa parte de minha geração, eu tinha uma preocupação política diretamente relacionada com a situação do país, vivendo sob o regime militar.

Já tive oportunidade de comentar em outros contextos que a própria motivação de estudar as camadas médias copacabanenses estava associada à vontade de conhecer as características de visão de mundo que levaram grande parte delas a apoiar o movimento/golpe contra o governo, legalmente constituído, em 1964. O que a leitura dos clássicos da antropologia me dava era uma crescente convicção, ao ler Malinowski, Evans-Pritchard 
e Edmund Leach, entre outros, que o conhecimento de que dispúnhamos sobre a sociedade brasileira e, particularmente, sobre suas camadas médias era superficial, estereotipado e esquemático. As etnografias da história da antropologia, que fui lendo no decorrer de minha formação, me indicavam a necessidade de procurar ir um pouco mais fundo na dimensão cognitiva e no ethos dos grupos e das categorias sociais que buscava entender. As camadas médias foram e continuam sendo para mim e diversos orientandos tema prioritário. Mas logo se evidenciou a importância de compreendê-las em diversas instâncias e contextos de relacionamento (Salem 1986). Para isso, a tradição antropológica do trabalho de campo e da observação participante era uma referência crucial.

Não se tratava de começar do zero, mas de reler inclusive obras, como a de Gilberto Freyre, que traziam preciosas reflexões sobre a cultura e os modos de vida brasileiros. O estudo de grupos e categorias desviantes permitia fazer perguntas sobre fronteiras e relações em que valores morais e regras sociais marcavam não só a situação dos acusados e discriminados mas, principalmente, dos que impunham ou tentavam impor regras, além destas propriamente ditas, ou seja, a pretensão era buscar, através da identificação do interditado, do que não pode, os padrões dominantes e sua eficácia em determinado quadro sócio-histórico. Tratava-se de criticar a noção de patologia social. A coletânea Desvio e divergência por mim coordenada e publicada em 1974, reunindo trabalhos meus e de alunos de curso, foi um marco nessa caminhada. Houve quem não compreendesse muito bem do que se tratava. Pessoas que hoje adotam entusiasticamente a bibliografia interacionista, na ocasião julgavam que falar em desvio era encampar uma visão preconceituosa, em vez de perceber, o que parecia óbvio, que se tratava de um estudo de um sistema de relações.

O fato é que, ao pesquisar prostitutas, homossexuais, pessoas acusadas de transgressões dos mais variados tipos, estávamos lidando com os portadores e, principalmente, com os cruzados, defensores dos valores e dos padrões mais convencionais. Portanto, deslocava o foco de atenção para as camadas médias de um modo geral, inclusive para as nossas famílias, à medida que nas histórias de vida ficavam evidenciadas atitudes e posturas comuns não só a conhecidos, mas a muitos de nossos pais, tios, avós etc. Parece-me importante sublinhar que esta foi uma das contribuições mais significativas da antropologia que eu, vários de meus alunos e alguns colegas dedicamo-nos a desenvolver. As grandes cidades, onde vivíamos, em suas numerosas e densas redes, apresentavam-se como desafio.

Assumimos o estudo de nosso meio, de nossas vidas, como algo relevante para a antropologia que, por sua vez, contribuiria de modo significativo 
para uma compreensão mais rica e sutil da sociedade em que vivíamos. É nesse contexto que publico o artigo "Observando o familiar" (1978) que, a partir de um diálogo com Roberto DaMatta (1978), colocava em questão a natureza do conhecimento diante do familiar. Afirmava que ter familiaridade com fatos, situações e mesmo pessoas não significava conhecê-las, pois se tratava de outra ordem de significados. Conhecer exigiria de nós um esforço de aproximação e distanciamento que poderia fornecer indicações para uma compreensão mais complexa dos fenômenos em que estávamos diretamente envolvidos, através de experiência, emoções, sentimentos e formas de classificação internalizadas. Isto era visto como um grande desafio, mas enfrentá-lo era essencial para que pudéssemos estabelecer pontes entre a tradição antropológica e, em geral, a produção de conhecimento sobre a nossa sociedade. Nesse sentido, a aproximação e o diálogo com outras disciplinas, como a psicanálise e a história da cultura, assim como as artes em geral, foi sempre altamente profícuo.

Não me esqueço que o filme Opinião pública, de Arnaldo Jabor (1967), foi uma referência estimulante quando mergulhei em minha pesquisa copacabanense. A literatura, especificamente, fosse a nacional ou a internacional, muito me ajudou e a diversos alunos meus (Velho 1988). No meu caso particular, as obras de Marcel Proust e Thomas Mann tiveram um papel crucial para despertar sensibilidades e levantar pistas sobre subjetividade, trajetórias e redes sociais. Em termos brasileiros, Machado de Assis também desempenhou um papel importante, sobretudo os seus Memórias póstumas de Brás Cubas e Memorial de Ayres. O diálogo com a História sempre existiu, pois desde a adolescência interessava-me por uma aproximação e de fato me acheguei, fosse através de historiadores ou de romances históricos. De Alexandre Dumas e Walter Scott a Georges Duby e Jacques Le Goff, entusiasmei-me, fui desenvolvendo receptividade e atenção para com os fenômenos históricos, fortemente estimulados pelo marxismo, como através do 18 Brumário de Luís Bonaparte (Marx 1963 [1869]). Lukács, Hauser e Lucien Goldmann foram leituras preciosas. Mais adiante Panovski, Bakhtin, Ginzburg e Norbert Elias fortaleceram os laços com uma história cultural de alto interesse antropológico. Inevitavelmente, entramos também na importância do pensamento filosófico. Só isso daria um gigantesco texto de comentários.

Mas o que quero frisar, em se tratando de um depoimento pessoal, é que fiz a minha combinação entre marxismo e existencialismos. Albert Camus e Jean-Paul Sartre, com seus pontos comuns e diferenças foram leituras marcantes, cuja importância não há como diminuir. Certamente, a questão da subjetividade e a preocupação com a noção de projeto têm suas origens principais no período em que me debrucei sobre os seus textos. Quando anos 
mais tarde me aproximei dos escritos de Alfred Schutz, já existia um terreno favorável para receber parte de suas reflexões. As relações entre marxismo, existencialismo e fenomenologia constituíram-se nas bases da influência filosófica do meu trabalho, embora fragmentada e irregular. Sem dúvida, a leitura de Platão, Cícero e Montaigne acompanhou grande parte de minha vida e até hoje são companhias bem-vindas. Na realidade, podemos ver como são complexas, confusas até certo ponto e eventualmente contraditórias as origens e as bases para o desenvolvimento de um modo próprio de olhar e analisar o mundo.

Os artistas, em geral, e alguns escritores, em particular, independentemente de uma discussão mais de natureza estética, desenvolveram através de suas obras análises, captando, muitas vezes com grande sutileza e argúcia, características fundamentais da sociedade em que viviam. Além dos supracitados Proust, Thomas Mann e Machado de Assis, não posso deixar de mencionar, entre os autores que me influenciaram e certamente a outros cientistas sociais, Goethe, Balzac, Flaubert, Dickens, Stendhal, Tolstoi, Dostoievski, Melville, Eça de Queirós, Graciliano Ramos, Fernando Pessoa, Jorge Luis Borges etc. Homero e o teatro grego desde cedo, aliás, me fascinaram e marcaram, assim como a tantos intelectuais de nossa tradição ocidental. Ésquilo, Sófocles e Eurípides passaram a ser referências que ultrapassavam os limites de classificação de saber convencional.

O período 1960-1970 foi aquele em que mais frequentei o teatro. Meu pai tinha em sua biblioteca praticamente toda a obra de Shakespeare, de que li parte, principalmente as peças mais famosas. Até hoje, a de que mais gosto é o Rei Lear que me marcou profundamente, sem omitir o encantamento provocado por Hamlet, A tempestade, Ricardo III, Otelo e várias outras. Cabe destacar, no meu caso particular e, também, para boa parte dos meus contemporâneos universitários, a intensa relação com o cinema. Não posso pensar na minha formação sem prestar tributo a Orson Welles, Fellini, Bergman, Eisenstein, Breson, Kurosawa, Glauber Rocha, Nelson Pereira dos Santos, Buñuel, Stanley Kubrick, Antonioni, Visconti, Rossellini, Vittorio de Sica, Godard, e assim por diante. Como movimentos, o Neorrealismo italiano, a Nouvelle Vague francesa e o Cinema Novo brasileiro foram fundamentais para estimular preocupações, refinar o olhar, fora as percepções sobre narrativa e, certamente, para o levantamento de temáticas relevantes, sobretudo aquelas em que as biografias individuais cruzavamse e expressavam situações históricas e contextos sociais favoráveis a uma análise antropológica.

Efetivamente, desde o início de minha carreira, a sociologia e a antropologia da arte constituíram-se não só em preocupações importantes, mas 
em estímulo para meus trabalhos. O primeiro artigo que publiquei, assim como uma série de coletâneas que organizei focalizam essa temática que jamais me abandonou (Velho 1966, 1967a, 1967b, 1967c, 1969, 1977b, 1988). Ou não nos abandonamos. Fui reencontrar, em outras bases, diálogo com essa área através, em grande parte, dos trabalhos de Howard S. Becker, principalmente o seu livro Art worlds (1982). Foi uma das melhores maneiras que encontrei de integrar as vertentes de uma história da arte com a análise sociológica de sua construção. Era mais uma oportunidade de estabelecer pontes entre diferentes tradições, fazendo o meu coquetel particular. Toda essa amplitude e heterogeneidade caracterizaram essa linha de trabalho que ficou mais identificada com o que se chama de Antropologia urbana. A essas alturas já fica mais do que evidente como ela engloba ou se relaciona com temas tão variados como a Antropologia das sociedades complexas, Indivíduo e sociedade, Interacionismo e desvio, Sociologia e antropologia da arte, História da cultura, provocando efeitos nas 90 teses e dissertações que orientei até 2010. Não creio que o orientador seja uma espécie de demiurgo, mas sim um interlocutor privilegiado que dialoga com autores que têm seus próprios perfis e interesses. O que desejo frisar é que, desde meados dos anos 1970, eu e meus alunos já trabalhávamos não só com o fenômeno urbano, no seu sentido mais específico, mas com a problemática mais geral da teoria antropológica no que concerne à sociedade complexa modernocontemporânea, tendo o Brasil como foco principal, embora não exclusivo.

As duas primeiras dissertações que orientei foram sobre instituição psiquiátrica e movimentos sociais. Seguiram-se trabalhos de mestrado e doutorado, totalizando 90, sobre homossexualismo masculino, moradia urbana, umbanda e espiritismo, literatura através de diversos autores, menores institucionalizados, idosas e suas identidades, vários sobre família e parentesco, futebol, bairros, subúrbio e periferia, capoeira, prostituição, música popular como samba, funk, hip hop, heavy metal e forró, militares, jornalistas, escolas, teatro, movimento feminista, hábitos alimentares, cultura popular e folclore, favelas e comunidades, política, novelas, museus, ethos de elites, sociabilidade em espaços públicos, correspondência de políticos, identidades em Moçambique, diplomatas e sua formação, autores como Rui Barbosa, Mário de Andrade, Béla Bartók, João do Rio, Nelson Rodrigues, Academia de Letras, solidão, mediação, prisões, casais, adoção, separação, representações de pessoa e individualismo, terapias, modernismo, condomínios, minorias étnico-religiosas, usos da informática, cinema pornô, salões de beleza, empregadas domésticas, diversos tipos de identidades urbanas e assim por diante. ${ }^{2}$ É claro que esses assuntos se cruzavam, complementavamse e, no decorrer do tempo, permitiram a formação de equipes de trabalho 
e grupos de estudo, não só por possíveis afinidades temáticas como áreas de estudo, mas sobretudo por interesses mais gerais relacionados à teoria antropológica e ao trabalho de campo. Assim, através de temas aparentemente díspares, foi possível abrir e manter canais de diálogo e aproximação, com o uso de autores comuns ou próximos, correntes de pensamento e compartilhamento nos desafios de pesquisa e escrita. Minha trajetória e meus interesses intelectuais permitiram e incentivaram que esses casos de numerosos e diversificados trabalhos se incorporassem a uma visão que já, desde o início, cultivara. Creio que nos meus trabalhos pessoais é impossível dissociar, por exemplo, a perspectiva interacionista de uma preocupação com diferenciação sociológica inspirada por Marx e Weber, e de uma forte marca culturalista tanto na tradição antropológica quanto na histórica. Simmel foi fundamental para lidar com as ambiguidades e os paradoxos da continuidade e do conflito na vida social, além de abrir infindáveis focos e temas de reflexão que ultrapassaram as fronteiras disciplinares mais convencionais.

Houve um período, nos primeiros tempos do PPGAS, no Museu Nacional, que este apresentava três grandes áreas de concentração de estudo e pesquisa: Etnologia, Sociedades Camponesas e Antropologia urbana. É interessante acompanhar esse período de 42 anos desde a criação do Programa. Os temas iniciais estavam inevitavelmente associados a certos projetos de pesquisa voltados para o estudo de sociedades indígenas e situações de contato. A problemática das frentes de expansão e campesinato logo foram assumindo importante espaço e destaque. A minha dissertação de mestrado, sobre camadas médias copacabanenses, foi a terceira a ser defendida e, quando retornei dos Estados Unidos em 1972, passei a dar cursos focalizando primeiro uma Antropologia urbana mais genérica e, depois, dentro de um vasto campo que viria a ser denominado de Indivíduo e sociedade, o estudo de grupos desviantes, fortemente inspirado por autores interacionistas, especialmente Goffman e Becker. O fato de Utopia urbana e da coletânea Desvio e divergência terem sido publicados, respectivamente, em 1973 e 1974 divulgou essa vertente de ciências sociais que passava a ser desenvolvida num programa de Antropologia Social. Tornei-me doutor em 1975 e passei a orientar formalmente alunos que produziram os trabalhos supracitados. Mesmo antes disso, já participava, informalmente, através de diálogos e cursos, da orientação de alguns alunos. O fato é que pesquisas na e sobre a cidade multiplicavam-se em linhas as mais diversificadas e originais.

Há que se ressaltar a importância do papel de Roberto DaMatta em abrir espaços e cruzar fronteiras. Ph.D. por Harvard e com formação na área de Etnologia, rapidamente demonstrou como a tradição antropológica poderia ser produtiva ao se voltar para os mais variados temas, com destaque para 
a sociedade brasileira contemporânea. Particularmente importantes foram suas pesquisas e seus textos sobre rituais, cuja contribuição principal foi o livro Carnavais, malandros e heróis (1978). Muitos estudantes trabalharam sob sua orientação, e seus cursos de Teoria Antropológica foram de grande importância para várias gerações. Não cheguei a ser seu aluno, mas éramos colegas e vizinhos de sala. Nem sempre concordando, tivemos a oportunidade de conversar e trocar ideias sobre os mais variados temas, vivendo um tipo de experiência de diálogo hoje não muito fácil de ser encontrado. É interessante pensar que tínhamos tempo para conversar, algo hoje muito difícil em função das exigências e das demandas de relatórios, projetos e pressão do mundo burocrático da informática, em que resta pouco espaço fora das reuniões oficiais com suas regras, limitações e dos formulários e prazos que passaram a comandar a vida universitária. Além dos outros colegas cuja atuação foi muito significativa para o desenvolvimento inicial do PPGAS, há que ressaltar a ascensão das novas gerações com suas próprias preocupações e projetos originais. Estou falando de pessoas que hoje estão entre os 50 e 60 anos. Assim, novas linhas de pesquisa foram se desenvolvendo e emergiram temas antes ou desconhecidos ou pouco explorados. Ganharam mais espaço religião, política, economia, gênero, sexualidade, identidades étnicas, saúde etc.

Um dos pontos que acho importante comentar com um pouco mais de ênfase é minha relação com a chamada Escola de Chicago, aprofundada por meu crescente contato com Howard S. Becker a partir de 1976, depois de meu doutoramento. É significativo que tenha sido muito identificado com ela e, em outros contextos, com o interacionismo que corresponderia, para alguns, à dimensão mais teórica da referida Escola. Não custa insistir, seguindo autores como Becker, que não havia propriamente uma doutrina ou unidade teórica comum aos profissionais que, entre o final do século XIX e boa parte do século XX, estiveram ligados ao Departamento, primeiro de Sociologia e Antropologia e, depois de 1929, com a divisão efetuada, ao Departamento de Sociologia propriamente dito. Cabe destacar que autores pioneiros como W. Thomas e R. Park percorriam várias áreas de pesquisa e reflexão e dificilmente poderiam ser enquadrados num simples rótulo. O mesmo pode ser dito de vários de seus alunos e de pessoas de outras gerações.

É certo que existem algumas influências mais significativas, como as de G. Simmel e de G. H. Mead. É fundamental enfatizar que estes dois autores correspondem a linhas de pensamento não coincidentes e bastante distintas. O que certamente os aproximava era uma preocupação com os temas da subjetividade e da interioridade. Mas a noção de "cultura subjetiva" em Simmel diferencia-se bastante da noção de self de Mead. Não há dúvida de que a 
preocupação em relacionar indivíduo, biografia e sociedade constituiu-se em referência recorrente nos autores ligados a essas tradições. Por outro lado, o que era, sem dúvida, importante para esse universo de intelectuais era a preocupação com a pesquisa, contribuindo para que o foco no trabalho de campo aproximasse perspectivas sociológicas e antropológicas. Embora não houvesse barreiras intransponíveis entre métodos quantitativos e qualitativos, produziu-se uma linguagem comum a partir dos desafios da observação, das histórias de vida, da investigação de trajetórias e carreiras, entre outros.

Assim, a "Escola de Chicago" espalhou-se pelos Estados Unidos, por diversos departamentos e universidades mais como uma visão de pesquisa do que como uma doutrina ou uma teoria homogênea. As diferenças entre profissionais como Wirth, Blumer e Hughes foram importantes até para enriquecer o repertório de seus alunos, como Becker e Goffman. Pelos depoimentos de Becker $(1990,1996)$ e de outros colegas seus, através de entrevistas e artigos, ressalta-se que um relativamente pequeno número de docentes no pós-Segunda Grande Guerra lidava de um modo próprio com grande número de alunos, beneficiados e multiplicados por medidas de política educacional da época, como a G.I. Bill. Assim, havia uma intensa comunicação e relacionamento dentro do próprio corpo discente, com competição, trocas e influências recíprocas. Há muito mais para se dizer sobre a Escola de Chicago, mas o que eu gostaria de frisar é que o que mais me impressionou foi a variedade de alternativas, caminhos e estilos (Velho 2005). Li com prazer alguns dos autores, outros nem tanto. Paralelamente, às vezes, até antes e depois também, estudava Antropologia Social Britânica e Antropologia Cultural Norte-americana, além de autores-chave franceses para o meu desenvolvimento intelectual. Entre outros, com o risco de omissões, cito Evans-Pritchard, Raymond Firth, Edmund Leach, Clyde Mitchell, Elizabeth Bott, Edward Sapir, Ruth Benedict, Margareth Mead, Victor Turner, Clifford Geertz, Marshal Sahlins, Marcel Mauss, Maurice Halbwachs, Lévi-Strauss, Louis Dumont, Pierre Bourdieu, Michel Foucault etc.

Gostaria de assinalar, caracterizando a minha trajetória, que não me tornei intelectual através da antropologia. A minha formação, sobretudo, adveio da influência paterna, do Colégio de Aplicação em que fiz o curso secundário, de frequentador dos cursos do ISEB (Instituto Superior de Estudos Brasileiros) e dos meus interesses desde o início da adolescência, o que me levou a caminhar em direção às ciências humanas. A maior hesitação que tive foi entre história e antropologia, mas o campo da história, no Rio de Janeiro, estava muito enfraquecido, agravado pelas perseguições políticas e por interesses subalternos. Meu irmão Otávio Guilherme, oriundo do Colégio Militar, fizera o seu curso na Escola de Sociologia e Política da 
PUC. Ele e alguns dos seus colegas foram referências importantes (Velho 2001). A essas alturas da vida e da carreira, construindo a minha biografia retrospectivamente, vejo que desenvolvi uma vocação para a vida intelectual que depois passou pela Faculdade Nacional de Filosofia, pelo Instituto de Ciências Sociais da UFRJ, pelo PPGAS do Museu Nacional. As viagens aos Estados Unidos e, especificamente, o contato com Howard S. Becker também muito contribuíram para certo tipo de direcionamento.

Mas eu, como outros colegas, com certeza, não recebemos bem as tentativas de rotulação e classificação simplificadoras. Houve uma época em que eu me considerava marxista, lá pelos 17, 18 anos de idade. Hoje, vejo-me como um intelectual eclético, espero que no melhor sentido. Por uma série de circunstâncias e, até certo ponto, por projeto, desenvolvi um perfil em que o interacionismo e a fenomenologia são muito evidentes. Sobre esta última, cabe sublinhar a riqueza que encontrei na obra de Alfred Schutz (1971) que me proporcionou pontes entre várias áreas e interesses de conhecimento, inclusive a própria arte. Indiretamente, através das leituras dos autores da tradição de Chicago, relacionei-me também com o pragmatismo, sem jamais aprofundar-me especificamente. No entanto, o diálogo de Schutz com os trabalhos de William James, entre outros, deixou-me alerta para a formação intelectual da ciência social norte-americana, cujas relações com a Europa eram bem mais complexas do que supunha.

Creio que seja importante, embora não tão original agora, lembrar das próprias reflexões antropológicas que desenvolvemos. Deslocamo-nos através de nossas redes sociais entre vários mundos e níveis de realidade. Assim, literatura, história, filosofia, entre outras, são áreas que estão permanentemente presentes aflorando, ora de modo quase inconsciente, ora chamadas de forma deliberada e consciente para um trabalho de maior reflexão. O grande desafio é como orquestrar essa variedade de um modo minimamente consistente e proveitoso. Ficou muito claro para mim, por exemplo, a enorme importância da leitura de Em busca do tempo perdido, de Marcel Proust (1981 [1913-1927: $1^{\mathrm{a}}$ publ.]). ${ }^{3}$ Embora outros escritores, como Dickens, Balzac, Flaubert e Thomas Mann, como já foi mencionado, muito tivessem me impressionado, foi através da grande obra proustiana que tive o melhor encontro entre algumas de minhas preocupações centrais como antropólogo e, em termos mais amplos, com a minha percepção intelectual e estética do mundo e da vida.

Sem desejar simplificar e reduzir uma obra de arte tão significativa, cabe-me repetir o que já foi dito por vários comentadores, mas salientando alguns pontos. É mais do que sabida a importância do tempo em Proust e seus significados sutis e referências cruciais para o desenvolvimento da 
vida dos indivíduos e da sociedade. Há fortes relações com as ideias de Bergson. Associado a isto temos, de uma maneira única, a importância da memória como organizadora da subjetividade e das relações entre os indivíduos. Na obra em pauta, temos uma lição permanente sobre a complexidade das pessoas, tanto internamente, na sua subjetividade, como na sua participação na sociedade, através do trânsito social e de diferentes redes e esferas. Há uma verdadeira etnografia da vida da época e, sobretudo, de Paris como metrópole nos termos de Simmel (1908). Não se trata apenas de mostrar a variedade das relações, mas o significado que é atribuído a estas e suas repercussões sobre a vida de cada um. Claramente são identificados projetos na terminologia de Schutz. Percebe-se como indivíduos e grupos orbitam pela vida social, no decorrer do tempo, e mesmo simultaneamente, complexificando as suas identidades. Há muitas coisas visíveis e evidentes, através da observação da vida pública. Mas existe toda uma gama de mistérios, obscuridão, segredos, meias verdades que podem surpreender ou jamais serem descobertos nos processos de interação social. As pessoas se conhecem, se veem e se relacionam. Mas há sempre algo que não se sabe ou que pode surgir de repente, que altera o sentido e o significado das relações. As memórias são refeitas e reinterpretadas, alterando a percepção de si e dos outros. A descoberta possível de transgressões pode ilustrar, como casos limite, a dimensão quase que indecifrável da existência das pessoas em sociedade. Na cidade, em seus trânsitos, trilhas e anonimatos relativos, defrontamo-nos ainda de modo mais agudo com essa experiência de multipertencimentos e fragmentação.

Proust mostra, sobretudo, a densidade e não a obviedade da vida social, funcionando como uma espécie de vacina contra os reducionismos simplificadores do pensamento, ou seja, aprendi mais ainda, através de Proust, sobre a complexidade dos indivíduos e das relações sociais (Velho 1982). É importante levar em conta as aparências, mas é necessário ir além delas. Ao mesmo tempo é fundamental saber que, por maior que seja o nosso esforço de compreensão, haverá sempre algo que nos escapa. Isso, longe de ser negativo, torna-se um estímulo e uma razão para a maior modéstia de nossas pretensões. Sabemos que as relações erótico-amorosas permeiam boa parte da obra proustiana, nas mais diversas formas. É um alerta para o trabalho dos cientistas sociais, que não precisam se transformar em psicólogos para valorizar, prestar atenção nas emoções, nos desejos e afetos, tão importantes na sua dimensão sociocultural.

Certamente, as minhas reflexões sobre projetos e campo de possibilidades levaram-me a prestar atenção nas tensões entre as motivações ditas racionais e a força dos fatores ditos irracionais. A importância da vida 
simbólica, a eficácia das crenças e dos mitos, o peso das tradições e dos costumes misturam-se às intenções de transformação, de planejamento e de interferência na vida social. Esse jogo de contradições pode configurarse através do confronto entre grupos e categorias sociais, mas se dá internamente nos próprios indivíduos. Isto me leva a comentar um pouco mais sobre o meu trabalho na área de desvio e comportamento desviante. Como já disse, o que me interessava não eram os comportamentos em si, mas um sistema de relações que envolvia limites e fronteiras simbólicos e sociais. Claramente, a leitura do livro Outsiders, de Becker (1973), foi um estímulo para que aprofundasse as minhas próprias reflexões. Eu já lera e continuava lendo trabalhos de outra tradição em Ciências Sociais. Refiro-me à bibliografia que, entre outros autores, inclui Evans-Pritchard (1976 [1937]) e Mary Douglas (1970). As suas pesquisas e análises sobre acusações de feitiçaria levaram-me a estabelecer pontes entre interacionismo e essa vertente da Antropologia Social Britânica. Publiquei alguns textos nessa direção que, de algum modo, foram reconhecidos como inovadores e uma abertura de perspectivas (Becker 1963).

Aí voltamos ao que denominei de ecletismo que julgo positivo. O fato de transitar entre diferentes correntes teóricas e interpretativas pode ajudar não só os antropólogos, mas os cientistas sociais em geral para o desenvolvimento de suas ideias e formulações. A acusação é, portanto, a dramatização de relações que envolvem diferentes atores. Basicamente, temos acusados e acusadores. Mas há alguma variação quanto a matizes, nuances, mudanças de papel e de desempenho, com o potencial elevado de levantar questões e hipóteses sobre processos sociais mais abrangentes. Assim, as acusações de drogado e subversivo que analisei revelavam características próprias de uma conjuntura histórico-cultural (Velho 1976). Passavam-se em vários níveis, desde um que poderíamos chamar de micro, interno a famílias, como no nível do próprio Estado, numa dimensão mais abrangente. Na realidade, tratava-se de lidar com uma política do cotidiano, com passagens entre vários níveis, incluindo os aparentemente mais íntimos até instâncias de poder estatal.

Despertou-me a atenção, desde o início dos meus trabalhos, a problemática da doença mental e, através da leitura de autores tão diversificados como os ligados à antipsiquiatria, especialmente Laing e Cooper, e outros como Szaz, Scheff e o próprio Foucault, percebi o quão importante seria o esforço antropológico de estabelecer pontes e ampliar horizontes nessa área. A psicanálise era uma das principais referências intelectuais e existenciais da época (Velho 1998 [1975]). A chamada Escola de Personalidade e Cultura, com Sapir, Ruth Benedict, Margareth Mead e pensadores próximos como Bateson, voltava a ser fundamental para que, através de uma reflexão 
crítica sobre cultura e vida social, pudéssemos comparar não só diferentes sociedades mas, no nosso caso, tentar desvendar as diferenças internas das sociedades complexas moderno-contemporâneas, como a brasileira. Nesse sentido, a própria problemática do desvio e das acusações poderia ser analisada, levando em conta, de um modo mais sistemático, linguagem, códigos e redes de significado. Portanto, de algum modo, retomava o ponto de vista de relativismo cultural, procurando estabelecer vínculos com um pensamento mais crítico-sociológico. A partir desta perspectiva, mais uma vez, o diálogo entre antropologia e história constituiu-se em referência básica.

Sem entrar em comparações e discussões paralelas, não posso deixar de citar a leitura de Clifford Geertz e Marshall Sahlins como decisiva na complexificação dessas preocupações. Através da cultura e da conjuntura histórica, tínhamos elementos para colocar em questão as noções de normalidade e anormalidade. As diferenças culturais e as transformações históricas levavam-nos a dar uma atenção às particularidades, mas também a uma visão mais universalista das sociedades humanas.

Há uma fase em minha carreira, a partir de meados dos anos 1970 que, embora não tenha desaparecido, teve seu maior desenvolvimento até o início dos anos 1990, em que tive oportunidade de dialogar e debater com psicólogos, psiquiatras e psicanalistas. A problemática do individualismo e suas relações com hierarquia, aproximando Simmel e Dumont, era um dos temas de interesse, assim como a retomada e as implicações da noção de cultura (Duarte 2000). É difícil delimitar as fronteiras entre os temas que pesquisei e orientei neste vasto mundo denominado Antropologia urbana. Certamente estarei omitindo alguns dos mais importantes. Mas, fazendo pontes com o que disse acima, não há como deixar de enfatizar a importância e o interesse na área de família e parentesco que atravessam dezenas de trabalhos meus e de alunos (Fonseca 2010). Focalizavam-se questões de geração e pesquisas específicas sobre idosos e jovens, com maior ou menor ênfase na problemática de gênero. O estudo de casais, modos alternativos de convivência, emergência de novos padrões de relacionamento amoroso e co-habitação são outros focos de análise.

A vida urbana em geral, a organização social do espaço, os bairros, as atividades políticas e de mobilização dos mais variados tipos constituíram-se também em assuntos que me interessavam desde a Utopia urbana. As manifestações e as relações entre os diferentes níveis de cultura, implicando dinâmicas de poder, reinvenção e construção de novas linguagens artístico-culturais, a identificação de mundos e movimentos de alguma especificidade, mas que permitissem comparações, foram alguns dos vetores principais dessa produção avaliada retrospectivamente. Muitas dessas ideias 
que aparecem são discutidas em alguns dos meus livros, como Individualismo e cultura e Projeto e metamorfose. Outras aparecem em coletâneas que organizei só ou em co-autoria.

O Rio de Janeiro tem sido o principal, embora não exclusivo, território de pesquisa. Neste, desde a zona sul, passando pela zona norte, Baixada Fluminense, subúrbios e periferias, trabalhos sobre múltiplos temas foram feitos. Outros centros, maiores ou menores, como São Paulo, Lisboa, Boston, Curitiba, Porto Alegre, Florianópolis e "cidades do interior", também foram campo de pesquisa, através de assuntos variados, cruzando a estrutura social e diferentes fronteiras culturais. Sem dúvida, há uma grande concentração de esforços na região metropolitana do Rio, por razões logísticas e por um projeto meu claro, inicial, de tomá-la como "cidade-laboratório". Só que o que se passava e era encontrado não cabia num modelo espacial-ecológico, multiplicando-se e fragmentando-se em vários mundos, redes sociais, correntes culturais, tornando o desafio ainda mais fascinante e provocador.

Os bairros, as "regiões morais", as diferentes áreas da cidade precisam ser compreendidas por suas identidades, não de modo estático, mas através dos trânsitos e das diferentes representações que geravam comunicação e também impasses com conflitos que poderiam colocar em questão a própria continuidade dos processos de interação social básicos. Assim, defrontei-me como pesquisador e cidadão com o acelerado agravamento do que se denominou violência urbana. Esse fenômeno atingiu, em termos amplos, a sociedade brasileira e, com particular dramaticidade, o Rio de Janeiro. Sabíamos, desde o início de nossas reflexões, da importância da dimensão constitutiva da violência para a própria formação de nossa sociedade. Não é o caso, aqui, de retomar toda a longa e complexa discussão e as análises sobre o processo sócio-histórico que evidenciam essas características. Reconhecíamos que a pobreza e a desigualdade eram variáveis importantes para a criação de um quadro com potencial de conflito, muitas vezes manifestado em episódios sangrentos de variados tipos, como situações que poderiam apresentar dimensões políticas e religiosas, direta ou indiretamente associadas a carências e à exploração.

O que tem ocorrido nas últimas décadas é a disseminação de uma "cultura da violência" que veio se avolumando, assumindo proporções que colocam em xeque o cotidiano de praticamente todos os segmentos sociais. Assaltos, sequestros, roubos, agressões, assassinatos são algumas das modalidades pelas quais se manifesta o fenômeno. É inegável que essa expansão da criminalidade e dos riscos inerentes aparece associada ao tráfico de drogas e de armas. Hoje, o uso de drogas é bastante disseminado pelo mundo. Cartéis, quadrilhas e gangues surgem e se desenvolvem mais em algumas sociedades do que em outras. Lamentavelmente, o Brasil é um dos países 
que se destacam pelo volume e pela intensidade da atividade criminosa. É evidente que existe uma motivação econômica que vai além da luta pela sobrevivência mais elementar. Interesses diversificados multiplicam-se, alimentando e produzindo desdobramentos dessas redes que alcançam, de vários modos, uma dimensão internacional, numa perspectiva globalizada. O que mais tem me chamado a atenção é o uso da violência não só como meio, mas como fim em si mesmo, ou seja, há pessoas e grupos que se dedicam e possivelmente se comprazem com o exercício da violência.

O Rio de Janeiro, como já foi dito, por uma série de circunstâncias que temos discutido e pesquisado, aparece como um dos casos limite da sociedade nacional. ${ }^{4}$ Diversos cientistas sociais e muitas pesquisas têm enfrentado esse desafio. O fenômeno apresenta múltiplas dimensões e produz efeitos variados. A questão básica da segurança pública implica considerar, prioritariamente, as relações do poder público com a sociedade civil. Assim, a corrupção, o abuso de poder, o uso indiscriminado da força e a ineficiência colocam em xeque não só os responsáveis diretos pelo combate à criminalidade, mas as mais diversas instâncias do mundo político-burocrático. Assim, a polícia, o Judiciário, o Legislativo e o Executivo têm sua legitimidade comprometida diante da continuidade e do recrudescimento das atividades criminosas. Sabe-se que parte considerável da região metropolitana do Rio de Janeiro é controlada por grupos criminosos, sejam traficantes, sejam milicianos. De uma forma ou de outra, a respeitabilidade e a confiança nos órgãos de segurança é mínima, chegando à desmoralização. Há quem fale em anomia e desorganização social. Certamente é inegável que, embora limitada, a expressão "crise de valores" sugere a necessidade de pensar a violência a partir de uma visão antropológica.

Desta forma, não estou falando de Antropologia urbana enquanto subárea, mas como ponto de encontro de pesquisas e análises em que o universo simbólico e de representações seja cada vez mais incorporado às pesquisas e às políticas públicas. Creio que, com todas as precauções e modéstia, tratase de um dos caminhos mais importantes para o desenvolvimento e a maior relevância de nossa área de investigação, através da recuperação, da renovação e da aproximação das análises de significados e dos processos de ação e interação social. Ou seja, é importante cruzar as fronteiras disciplinares e as tradições específicas, num esforço de aproximar diferentes contribuições que possam ampliar nossa concepção de trabalho intelectual. Isto tem sido particularmente importante para mim nos últimos anos, quando tenho buscado comparar experiências e visões de mundo de diferentes gerações do universo de camadas médias. Trata-se de um relativo privilégio poder conhecer e lidar com categorias socioetárias distintas. Mais do que nunca, 
o recurso a distintas áreas do conhecimento tem se revelado necessário e crucial em função da complexidade das questões envolvidas.

O próprio pesquisador é, em parte, personagem das histórias e das narrativas que colhe. Assim como as pessoas do universo pesquisado, desloca-se entre diferentes planos e níveis da realidade, num jogo retrospectivo e prospectivo de memórias e projetos em que a subjetividade está sempre presente. A antropologia nas metrópoles e nos grandes centros urbanos em geral defronta-se cada vez mais com novos e velozes sistemas de comunicação e informação, que se agregam e interagem com redes de relações e categorias sociais das mais variadas características. Embora isso se desenvolva nas sociedades como um todo, num processo de interação entre correntes de tradição cultural, mais ou menos longevas (Barth 1989), é no meio urbano contemporâneo, com sua complexidade e dinamismo, que esses fenômenos aparecem com mais intensidade e nitidez. O estudo das gerações, seus valores, atitudes e projetos sugerem trilhas e possibilidades de conhecimento em que a interdisciplinaridade torna-se cada vez mais prioritária.

Recebido em 11 de janeiro de 2011

Aprovado em 10 de fevereiro de 2011

Gilberto Velho é Professor Titular e Decano do Departamento de Antropologia do Museu Nacional / UFRJ. E-mail: < gvelho@terra.com.br >

\section{Notas}

${ }^{1}$ É evidente que existem outras versões de diversos profissionais e grupos de pesquisa que têm se dedicado a essa área da antropologia. Hoje, há uma rica e diversificada produção, cujos méritos e características foram recentemente analisados por Eckert (2010).

${ }^{2}$ A lista de dissertações e teses que orientei, com seus respectivos autores, pode ser encontrada no site do PPGAS/Museu Nacional: http://www.ppgasmuseu.etc.br

${ }^{3}$ Em busca do tempo perdido foi publicado em sete volumes entre 1913 e 1927. Após o polêmico parecer de recusa da Editora Gallimard, o primeiro volume foi 
publicado às expensas do autor na pequena editora Grasset. Contudo, muito rapidamente, a Gallimard recuou em sua posição original, publicando todos os demais volumes da obra.

${ }^{4} \mathrm{O}$ "temos" refere-se a vários pesquisadores que nas últimas décadas têm se dedicado a investigar, sob múltiplos aspectos, a temática da violência, tendo como foco o Rio de Janeiro. São trabalhos importantes, já citados por mim anteriormente em outros textos.

\section{Referências bibliográficas}

BAKHTIN, Mikhail M. 1987. A cultura popular na Idade Média e no Renascimento: o contexto de François Rabelais. São Paulo: Hucitec/Edusp; Brasília: UnB.

BARTH, Fredrik. 1989. "The analysis of culture in complex societies". Ethos, 54(III-VI): 120-142 [Publicado em português em BARTH, Fredrik. 2000. "A análise da cultura nas sociedades complexas". In: Fredrik Barth \& Tomke Lask [orgs.], O guru, o iniciador e outras variações antropológicas. Rio de Janeiro: Contra Capa].

BATESON, Gregory. 1985. Steps to an ecology of mind. Nova York: Balantine Books.

BECKER, Howard S. 1963. "Outsiders". In: Outsiders:studies in the sociology of deviance. Nova York: The Free Press. pp.1-18 [Publicado em português em BECKER, H. S. 2008. Outsiders: estudos de sociologia do desvio. Rio de Janeiro: Zahar].

1977. Sociological work: method and substance. New Brunswick: Transactions. 1982. Art worlds. Berkeley/ Los Angeles: University of California Press. 1990. "Uma entrevista com Howard S. Becker". Revista Estudos Históricos, 3(5):114-36.
1996. "A Escola de Chicago". Mana: Estudos de Antropologia Social, 2(2):177188.

2007. Talking about society. Chicago: University of Chicago Press. [Publicado em português em BECKER, $\mathrm{H}$. S. 2009. Falando da sociedade. Rio de Janeiro: Zahar].

BENEDICT, Ruth. 1934. Patterns of culture. Boston: Houghton Mifflin.

BENJAMIN, Walter. 1959. Oeuvres choisies. Paris: Julliard.

BERGSON, Henri. 1896. Matière et mèmoire: essai sur la relation du corps avec l'esprit. Paris: Alcan [Publicado em português em BERGSON, Henri. 1999. Matéria e memória: ensaio sobre a relação do corpo com o espírito. São Paulo: Martins Fontes].

BLUMER, H. 1969. Symbolic interactionism: perspective and method. New Jersey: Prentice Hall.

BOTT, Elizabeth. 1972. Family and social network. Londres: Tavistock [Publicado em português em BOTT, Elizabeth. 1976. Família e rede social. Rio de Janeiro: Francisco Alves].

BOURDIEU, Pierre. 1970. La reproduction. Éléments pour une théorie du système d'enseignement. Paris: Minuit [Publi- 
cado em português em BOURDIEU, Pierre. 1975. A reprodução. Rio de Janeiro: Francisco Alves].

. 1972. Esquisse d'une théorie de la pratique. Genebra: Droz.

_. 2003. O amor pela arte: museus de arte na Europa e seu público. Porto Alegre: Editora Zouk. . 2007. A distinção: crítica social do julgamento. Porto Alegre: Editora Zouk.

COOPER, David. 1967. Psiquiatria e antipsiquiatria. São Paulo: Perspectiva.

DAMATTA, Roberto. 1978. "O ofício do etnólogo ou como ter 'anthropological blues'". In: Edson de Oliveira Nunes (org.), A aventura sociológica. Rio de Janeiro: Zahar.

1979. Carnavais, malandros e heróis: para uma sociologia do dilema brasileiro. Rio de Janeiro: Zahar Ed.

DOUGLAS, Mary (org.). 1970. Witchcraft, confessions and accusations. Londres: Tavistock.

DUARTE, Luiz Fernando Dias. 2000. "Person and psychologization in Brazil: a study in moral regulation". Journal of Latin American Anthropology, 4(2)/5(1).

DUBY, Georges. 1991. L'histoire continue. Paris: Odile Jacob [Publicado em português em DUBY, Georges. 1993. A história continua. Rio de Janeiro: Zahar].

DUMONT, Louis. 1966. Homo hierarchicus: essai sur le système des castes. Paris: Gallimard.

_. 1977. Homo aequalis: genèse et épanouissement de l'idéologie économique. Paris: Gallimard.

ECKERT, Cornelia. 2010. "Cidade e política: nas trilhas de uma antropologia da e na cidade no Brasil". In: Luiz F. D. Duarte (org.), Horizontes das ciências sociais no Brasil. São Paulo: ANPOCS.

ELIAS, Norbert. 1990. O processo civilizador. Rio de Janeiro: Zahar.
EVANS-PRITCHARD, E. E. 1976 [1937]. Witchcraft, oracles and magic among the Azande. Londres: Oxford University Press [Publicado em português em EVANS-PRITCHARD, E. E. 2005. Bruxaria, oráculos e magia entre os Azande. Rio de Janeiro: Zahar].

FAORO, Raymundo. 1975 [1958]. Os donos do poder: formação do patronato político brasileiro. São Paulo: USP.

FERNANDES, Florestan. 1965. A integração do negro na sociedade de classes. São Paulo: Dominus/EdUSP. 1975. A revolução burguesa no Brasil. Rio de Janeiro: Zahar.

FIRTH, Raymond. 1961. Elements of social organization. Londres: Watts [Publicado em português em FIRTH, Raymond. 1974. Elementos da organização social. Rio de Janeiro: Zahar]. FONSECA, Claudia. 2010. "Família e parentesco na antropologia brasileira contemporânea". In: Luiz F. D. Duarte (org.), Horizontes das ciências sociais no Brasil. São Paulo: ANPOCS.

FOUCAULT, Michel. 1961. Histoire de la folie. Paris: Plon [Publicado em português em FOUCAULT, Michel. 1977. A história da loucura na Idade Clássica. São Paulo: Perspectiva]. . 1975 [1968]. Doença mental e psicologia. Rio de Janeiro: Tempo Brasileiro.

FREYRE, Gilberto. 1933. Casa grande e senzala: formação da família brasileira sob o regime da economia patriarcal. Rio de Janeiro: José Olimpio. . 1936. Sobrados e mucambos: decadência do patriarcado rural e desenvolvimento urbano. Rio de Janeiro: José Olimpio. 1957. Ordem e progresso. Rio de Janeiro: José Olimpio.

FURTADO, Celso. 1969 [1920]. Formação econômica do Brasil. São Paulo: Editora Nacional.

GEERTZ, Clifford. 1973. The interpretation of cultures. Nova York: Basic Books 
[Publicado em português em GEERTZ, Clifford. 1978. A interpretação das culturas. Rio de Janeiro: Zahar]. 1988. Works and lives: the anthropologist as author. Stanford: Stanford University Press.

GINZBURG, Carlo. 1987. O queijo e os vermes: o cotidiano e as ideias de um moleiro perseguido pela Inquisição. São Paulo: Companhia das Letras.

GOFFMAN, Erving. 1959. The presentation of self in everyday life. New York: Anchor Books [Publicado em português em GOFFMAN, Erving. 1975. A representação do Eu na vida cotidiana. Petrópolis: Vozes].

. 1961. Asylums - essays on the social situation of mental patients and other inmates. Nova York: Doubleday [Publicado em português em GOFFMAN, Erving. 1974. Manicômios, prisões e conventos. São Paulo: Perspectiva].

1963. Stigma: notes on the management of spoiled identity. Englewood Cliffs: Prentice-Hall [Publicado em português em GOFFMAN, Erving. 1975. Estigma: notas sobre a manipulação da identidade deteriorada. Rio de Janeiro: Zahar].

GOLDMANN, Lucien. 1955. Le dieu caché. Paris: Gallimard.

1964. Pour une sociologie du roman. Paris: Gallimard [Publicado em português em GOLDMANN, Lucien. 1967. Sociologia do romance. Rio de Janeiro: Paz e Terra].

HALBWACHS, Maurice. 1952 [1925]. Les cadres sociaux de La mémoire. Paris: Presses Universitaires de France.

HAUSER, Arnold. 1951. The social history of art. New York: Vintage Books.

HOLANDA, Sérgio Buarque de. 1936. Raízes do Brasil. Rio de Janeiro: José Olimpio. 1958. Caminhos e fronteiras. Rio de Janeiro: José Olimpio. 1969. Visão do paraíso: os motivos endêmicos do descobrimento e colonização do Brasil. São Paulo: Nacional/Editora da Universidade de São Paulo.

HUGHES, Everett C. 1971. The Sociological eye: selected papers on institutions and race. Chicago: Aldine Athernon.

JAMES, William. 1950 [1890]. Principles of psychology. Nova York: Dover Publications.

LAING, R. D. 1960. The divided self: an existential study in sanity and madness. Harmondsworth: Penguin.

LE GOFF, Jacques. 1957. Les intellectuels au Moyen Âge. Paris: Seuil.

LEACH, Edmund. 1954. Political systems of Highland Burma: a study of Kachin social structure. Harvard: Harvard University Press [Publicado em português em LEACH, Edmund. 1997. Sistemas políticos na Alta Birmânia: um estudo da estrutura social Kachin. São Paulo: Edusp].

LEEDS, A \& LEEDS, E. 1978. A sociologia do Brasil urbano. Rio de Janeiro: Zahar.

LÉVI-STRAUSS, Claude. 1962. La pensée sauvage. Paris: Plon. 1975. Antropologia estrutural. Rio de Janeiro: Tempo Brasileiro. . 1976. As estruturas elementares do parentesco. Petrópolis: Vozes.

LUKÁCS, Georg. 1960. Histoire et conscience de classe. Paris: Minuit. . 1962. La théorie du roman. Paris: Bibliothéque Médiations / Editions Gonthier.

. 1964. O significado presente do realismo crítico. Lisboa: Cadernos de Hoje.

MALINOWSKI, B. 1961. Argonauts of the Werstern Pacific. Nova York: E.P. Dutton \& Co. Inc.

MANNHEIM, Karl. 1982. Ideologia e utopia. Rio de Janeiro: Zahar.

MARX, Karl. 1963. "O Dezoito Brumário de Luis Bonaparte". In: K. Marx \& F. Engels. Obras escolhidas. Rio de Janeiro: Vitória. 
MARX, K. \& ENGELS, F. 1963. Obras escolhidas. Rio de Janeiro: Vitória.

MAUSS, Marcel. 1950. Sociologie et antropologie. Paris: PUF.

MEAD, George H. 1934. Mind, self and society. Chicago: Chicago University Press.

MEAD, Margaret. 1935. Sex and temperament in three primitive societies. Nova York: William Morrow [Publicado em português em MEAD, Margaret. 1969. Sexo e temperamento. São Paulo: Perspectiva].

MILLS, Wright C. 1956. The power elite. Nova York: Oxford University Press. . 1959. A imaginação sociológica. Rio de Janeiro: Zahar.

. 1976. A nova classe média. Rio de Janeiro: Zahar.

PANOFSKY, E. 1967. Architecture gothique et pensée scolastique. Paris: Les Editions de Minuit.

PARK, Robert E. 1916. "The city: suggestions for the investigation of human behavior in the urban environment". American Journal of Sociology, XX:577-612 [Publicado em português em PARK, Robert E. 1967. "A cidade: sugestões para a investigação do comportamento humano no meio urbano". In: Otávio G. Velho (org.). 1967. O fenômeno urbano. Rio de Janeiro: Zahar. pp. 29-72].

1967. On social control and collective behaviour. Chicago: University of Chicago Press.

PEIRANO, Mariza. 2008. "Brazil: 'otherness in context'". In: Deborah Poole (ed.), A companion to latin american anthropology. Oxford: Blackwell Publishing.

PRADO JÚNIOR, Caio. 1969 [1942]. Formação do Brasil contemporâneo. 9. ed . São Paulo: Brasiliense.

PROUST, Marcel. 1981. Em busca do tempo perdido (7 vols.). Porto Alegre: Editora Globo.
SAHLINS, Marshall. 1976. Culture and practical reason. Chicago: University of Chicago Press [Publicado em português em SAHLINS, Marshall. 1979. Cultura e razão prática. Rio de Janeiro: Zahar].

__. 1985. Islands of history. Chicago: University of Chicago Press. 2004. Apologies to Thucydides: understanding history as culture and vice versa. Chicago: University of Chicago Press.

SALEM, Tânia. 1986. "Família em camadas médias: uma perspectiva antropológica". Boletim Informativo e Bibliográfico de Ciências Sociais, 21.

SAPIR, Edward. 1924. "Culture, genuine and spurious". The American Journal of Sociology, 29(4):401-429.

SCHEFF, Thomas. 1977. Being mentally ill. Chicago: Aldine.

SCHUTZ, Alfred. 1970. On phenomenology and social relations. Chicago: The University of Chicago Press. pp.79-124 [Publicado em português em SCHUTZ, Alfred. 1979. Fenomenologia e relações sociais. Rio de Janeiro: Zahar]. 1971. Collected papers. Vol III. The Hague: Martius Nijhoff.

SIMMEL, Georg. 1964. Conflict. Nova York: The Free Press.

. 1971 [1908]. "The metropolis and mental life". In: Donald Levine (org.), On individuality and social forms. Chicago: University of Chicago Press. pp.340-48. [Publicado em português: SIMMEL, Georg. 1967. "A metrópole e a vida mental". In: Otávio G. Velho (org.), O fenômeno urbano. Rio de Janeiro: Zahar].

STRAUSS, Anselm. 1999 [1997]. Espelhos e máscaras: a busca de identidade. São Paulo: Edusp.

SZASZ, Thomas. 1961. The myth of mental illlness: foundation of a theory of personal conduct. Nova York: Harper 
\& Row [Publicado em português em SZASZ, Thomas. 1979 [1961]. O mito da doença mental. Rio de Janeiro: Zahar].

THOMAS, William I. 1966. On social organization and social personality. Chicago: Phoenix Books.

TRILING, Lionel. 1976. The liberal imagination: essays on literature and society. New York: Charles Scribner's Sons.

TURNER, Victor. 1969. The ritual process: structure and anti-structure. Chicago: Aldine.

VELHO, Gilberto (org.). 1966. Sociologia da arte I. Rio de Janeiro: Zahar.

1967a. "Para que sociologia da arte no Brasil?" Cadernos Brasileiros, ano IX, n.40, março/abril.

(org.). 1967b. Sociologia da arte II. Rio de Janeiro: Zahar.

(org.). 1967c. Sociologia da arte III. Rio de Janeiro: Zahar.

(org.). 1969. Sociologia da arte IV. Rio de Janeiro: Zahar.

1973. A utopia urbana: um estudo de antropologia social. Rio de Janeiro: Zahar.

. (org.). 1974. Desvio e divergência: uma crítica da patologia social. Rio de Janeiro: Zahar.

1976. "Accusations, family mobility and deviant behavior". Social Problems, 23(3) :268-275.

1977. "Cotidiano e política num prédio de conjugados". In: José Augusto Guilhon de Albuquerque (org.), Classes médias e política no Brasil. Rio de Janeiro: Paz e Terra. pp.145-152.

(org.). 1977. Arte e sociedade: ensaios de sociologia da arte. Rio de Janeiro: Zahar.

1978. "Observando o familiar". In: Edson de Oliveira Nunes (org.), A aventura sociológica. Rio de Janeiro: Zahar.

(org.). 1980. O desafio da cidade: novas perspectivas da antropologia brasileira. Rio de Janeiro: Campus.
1981. Individualismo e cultura: notas para uma antropologia da sociedade contemporânea. Rio de Janeiro: Zahar. . 1982. "Literatura e desvio". In: Alexandre Eulálio et al. (orgs.), Caminhos cruzados: linguagem, antropologia e ciências naturais. São Paulo: Brasiliense.

. 1986. Subjetividade e sociedade: uma experiência de geração. Rio de Janeiro: Zahar.

_. (org.). 1988. Literatura e sociedade. Rio de Janeiro: PPGAS/MN.

. (org.). 1990. Individualismo e juventude. Rio de Janeiro: PPGAS/MN.

1998 [1975]. Nobres \& anjos: um estudo de tóxicos e hierarquia. Rio de Janeiro: Ed. da Fundação Getúlio Vargas.

_. 2001. "Entrevista com Gilberto Velho". In: FERREIRA, Marieta de Moraes; CASTRO, Celso \& OLIVEIRA, Lúcia Lippi. Revista Estudos Históricos, 2(28).

_. 2002. Mudança, crise e violência: política e cultura no Brasil contemporâneo. Rio de Janeiro: Civilização Brasileira.

_. 2005. "Reflexões sobre a Escola de Chicago". In: Licia do Prado Valladares (org.), A Escola de Chicago: impacto de uma tradição no Brasil e na França. Belo Horizonte: UFMG/ Rio de Janeiro: IUPERJ.

. (org.). 2006 [1999]. Antropologia urbana: cultura e sociedade no Brasil e em Portugal. Rio de Janeiro: Zahar. \& ALVITO, Marcos (orgs.). 1996. Cidadania e violência. Rio de Janeiro: UFRJ/FGV.

_. \& KUSCHNIR, Karina (orgs.). 2001. Mediação, cultura e política. Rio de Janeiro: Aeroplano.

_. \& KUSCHNIR, Karina (orgs.). 2003. Pesquisas urbanas: desafios do trabalho antropológico. Rio de Janeiro: Zahar. 
VALLADARES, Licia do Prado (org.). 2005. A Escola de Chicago: impacto de uma tradição no Brasil e na França. Belo Horizonte: UFMG/ Rio de Janeiro: IUPERJ.

VELHO, Otávio G. (org.). 1967. O fenômeno urbano. Rio de Janeiro: Zahar.

WEBER, Max. 1967. A ética protestante e o espírito do capitalismo. São Paulo: Pioneira.

WHYTE, William Foote. 1973. Street corner society: the social structure of an Italian slum. Chicago: The University of Chicago Press [Publicado em português em WHYTE, William Foote. 2005. Sociedade de esquina: a estrutura social de uma área urbana pobre e degradada. Rio de Janeiro: Zahar].

WIRTH, Louis. 1938. "Urbanism as a way of life". The American Journal of Sociology, 44:110-132 [Publicado em português em WIRTH, Louis. 1967. "O urbanismo como modo de vida". In: Otávio G. Velho (org.), O fenômeno urbano. Rio de Janeiro: Zahar. pp. 97-122].

WOLFF, Kurt H. (org). 1964. The sociology of Georg Simmel. Nova York: The Free Press. 
Resumo

Este texto lida com a complexidade e o desenvolvimento da Antropologia Urbana. É também um relato da carreira do autor e suas relações com os diferentes campos do conhecimento, não apenas de Ciências Sociais, num sentido mais restrito, como sociologia e ciência política, mas também literatura, filosofia, história e artes em geral. O texto enfatiza a importância do cruzamento de limites e fronteiras com o objetivo de enriquecer linhas de pesquisa e pensamento. Entre outros grupos, cita a Escola Sociológica de Chicago e a Antropologia Social Britânica como exemplos importantes de trabalho interdisciplinar. Chama a atenção para a complexidade e a heterogeneidade da sociedade modernocontemporânea e para a importância de mobilizar diferentes tradições de trabalho e pesquisa, especialmente no que toca os estudos urbanos desenvolvidos nas grandes cidades e metrópoles.

Palavras-chave Metrópole, Heterogeneidade, Sociedade Moderno-Contemporânea, Interdisciplinaridade

\section{Abstract}

This text deals with the complexity and development of Urban Anthropology. It is also an account of the author's career and his relations with different fields of knowledge, not only Social Sciences like Sociology and Political Science, but also Literature, Philosophy, History and the Arts in general. The text emphasizes the importance of crossing borders and frontiers as a way of enriching different lines of research and thought. Among other groups he cites the Chicago School of Sociology and British Social Anthropology as important examples of interdisciplinary work. The author draws attention to the complexity and heterogeneity of modern contemporary society and to the importance of mobilizing different traditions of work and research, especially when dealing with urban studies centred on the big cities and metropolises.

Key Words Metropolis, Heterogeneity, Modern Contemporary Society, Interdisciplinarity 